\title{
A Pilot Clinical Study of Olfactory Mucosa Autograft for Chronic Complete Spinal Cord Injury
}

\author{
Koichi IwATsuKI, ${ }^{1}$ Fumihiro TAJIMA, ${ }^{2}$ Yu-ichiro OHNISHI, ${ }^{1}$ Takeshi NAKAmuRA, ${ }^{2}$ \\ Masahiro IsHIHARA, ${ }^{1}$ Koichi HOSOMI, ${ }^{1}$ Koshi NinOMIYA, ${ }^{1}$ Takashi MORIWAKI, ${ }^{1}$ \\ and Toshiki YOSHIMINE ${ }^{1}$
}

${ }^{1}$ Department of Neurosurgery, Osaka University Medical School, Suita, Osaka; ${ }^{2}$ Department of Rehabilitation Medicine, Wakayama Medical University, Wakayama, Wakayama

\begin{abstract}
Recent studies of spinal cord axon regeneration have reported good long-term results using various types of tissue scaffolds. Olfactory tissue allows autologous transplantation and can easily be obtained by a simple biopsy that is performed through the external nares. We performed a clinical pilot study of olfactory mucosa autograft (OMA) for chronic complete spinal cord injury in eight patients according to the procedure outlined by Lima et al. Our results showed no serious adverse events and improvement in both the American Spinal Injury Association (ASIA) Impairment Scale (AIS) grade and ASIA motor score in five patients. The preoperative post-rehabilitation ASIA motor score improved from 50 in all cases to 52 in case 2, 60 in case 4, 52 in case 6, 55 in case 7, and 58 in case 8 at 96 weeks after OMA. The AIS improved from $A$ to $C$ in four cases and from $B$ to $C$ in one case. Motor evoked potentials (MEPs) were also seen in one patient, reflecting conductivity in the central nervous system, including the corticospinal tract. The MEPs induced with transcranial magnetic stimulation allow objective assessment of the integrity of the motor circuitry comprising both the corticospinal tract and the peripheral motor nerves. We show the feasibility of OMA for chronic complete spinal cord injury.
\end{abstract}

Key words: olfactory mucosa autograft, spinal cord injury

\section{Introduction}

The inability of the spinal cord to regenerate after spinal cord injury (SCI) is due to the extremely limited regenerative capacity of most central nervous system (CNS) axons along with the hostile environment of the adult CNS, which does not support axonal growth. Furthermore, astroglial scarring occurs in chronic lesions. ${ }^{1)}$ Axonal regeneration is, in fact, initiated in the injured spinal cord but is blocked by glial scars. ${ }^{2)}$ For successful axonal regeneration to take place in tissue with a chronic complete SCI, a supportive local scaffold is first required. The olfactory mucosa is an excellent autologous scaffold. The neurons and sustentacular cells in the olfactory mucosa undergo constant renewal throughout life by proliferation of basal global stem cells. ${ }^{3-5)}$ Furthermore, the mucosa contains olfactory ensheathing cells, which have received much attention for their potential to repair SCI. ${ }^{6-9)}$

Received December 11, 2015; Accepted February 1, 2016
We performed a pilot clinical study of olfactory mucosa autograft (OMA) for chronic complete SCI in eight patients according to the procedure outlined by Lima et al. ${ }^{10)}$

\section{Materials and Methods}

Patients were individuals who had experienced an SCI more than 12 months previously and were chronically paraplegic. Our rationale for selecting chronic SCI patients (more than 12 months from injury) who had undergone 8 weeks of preoperative rehabilitation was to circumvent spontaneous recovery bias. ${ }^{11)}$ The inclusion criteria of this study were generally consistent with those of Lima et al. ${ }^{10}$ and consisted of American Spinal Injury Association (ASIA) Impairment Scale (AIS) scores $^{12)} \mathrm{A}$ or B; age 16-40 years; presence of a spinal cord lesion $\leq 3 \mathrm{~cm}$; absence of significant nasal and paranasal sinus pathology; and absence of additional serious medical problems including respiratory disturbance, brain disease, or psychological disturbance. 
Eight patients (six men, two women) were enrolled in the study. Demographic data, clinical findings, and imaging/radiological characteristics of the patients are presented in Table 1 . The mean age of the patients was $31.5 \pm 7.8$ years (range, 19-40 years). Lesions resulted from road traffic accident injuries in all patients. The mean lesion size on the maximum vertical axis as measured on both $\mathrm{T}_{1}$ - and $\mathrm{T}_{2}$-weighted magnetic resonance imaging (MRI) was $2.6 \pm 0.5 \mathrm{~cm}$ (range, $1.7-3 \mathrm{~cm}$ ). Seven patients were AIS grade A, and one patient was AIS grade B. The mean duration from the injury to OMA transplant was $108.5 \pm 105$ months (range, 17-297 months).

\section{Transplantation protocol and surgical procedure}

Our procedure essentially followed the report by Lima et al. ${ }^{10,13)}$ Surgical intervention was performed under general anesthesia with endotracheal intubation. All surgical procedures were performed by the same neurological and otolaryngological team. The surgical procedure was performed in three steps.

The first step was performed by the otolaryngologists. The patient was positioned supine. To harvest the olfactory mucosa graft, a transnasal endoscopic approach and instrumentation were used. After cleaning the nasal and olfactory space with povidone/iodine, vasoconstrictors were injected into the mucosa. A submucoperiosteal tunnel was created in the most posterior-superior region of the medial (septal) side of the olfactory groove, and sufficient tissue was collected to fill the spinal cord. Microbiological examination was performed before and during the operation just prior to transplantation. Reabsorbable packing was placed in the olfactory groove to avoid postoperative nasal bleeding.

Table 1 Summary of demographic and clinical characteristics of eight patients who received olfactory mucosa autografts

\begin{tabular}{lcccccc}
\hline $\begin{array}{l}\text { Case } \\
\text { no. }\end{array}$ & $\begin{array}{c}\text { Age at } \\
\text { OMA } \\
\text { (y) }\end{array}$ & Sex & $\begin{array}{c}\text { Months } \\
\text { post-SCI }\end{array}$ & $\begin{array}{c}\text { SCI } \\
\text { level }\end{array}$ & $\begin{array}{c}\text { Length } \\
\text { of } \\
\text { lesion } \\
\text { (cm) }\end{array}$ & $\begin{array}{c}\text { AIS } \\
\text { grade }\end{array}$ \\
\hline 1 & 40 & Male & 297 & T4/5 & 2.8 & A \\
2 & 19 & Female & 27 & T7/8 & 2.1 & A \\
3 & 25 & Male & 17 & T11/12 & 2.7 & A \\
4 & 37 & Male & 122 & T7/8 & 1.7 & A \\
5 & 25 & Male & 38 & T5 & 3 & A \\
6 & 40 & Female & 48 & T11-12 & 3 & B \\
7 & 32 & Male & 79 & T5-6 & 3 & A \\
8 & 34 & Male & 240 & T10 & 2.6 & A \\
\hline
\end{tabular}

AIS: ASIA Impairment Scale, OMA: olfactory mucosa autograft, SCI: spinal cord injury, T: thoracic.
The second step was performed by the neurosurgeons. The patient was positioned prone. The damaged spinal cord was exposed with a standard midline incision, posterior laminectomy, and opening of the dura mater. The damaged spinal cord was approached by a posterior midline myelotomy. The scar tissue of the lesion was removed within limits so as to not harm normal cord tissues and to expose the gross viable nervous tissue in both stumps.

The last step involved the transplantation of the olfactory mucosa into the SCI site. Before implantation, the graft was immersed in the cerebrospinal fluid that was collected by a lumbar intrathecal catheter after anesthesia and cut into small pieces to increase the surface area of the grafted tissue. Meninges and the superficial tissue layers were sutured into place. Wound clips were used to close the skin.

\section{Pre- and postoperative rehabilitation}

All patients underwent preoperative rehabilitation (15 h/week for a duration of 8 weeks) and postoperative rehabilitation ( $15 \mathrm{~h} /$ week for a duration of 48 weeks). Preoperative rehabilitation was carried out until immediately prior to the operation. Baseline measures were determined after preoperative rehabilitation, which was performed to ensure a stable neurological status. The rehabilitation included standard physical therapy strategies to encourage motor function at and below the lesion, enabling walking training as soon as possible.

\section{Outcome measures}

Safety and efficacy measures are presented in Table 2. Any improvements in AIS grade and/or lower extremity motor scores were considered evidence of true gains, because the ASIA motor score was 0 for both legs in all patients after preoperative rehabilitation. The pre- and postoperative assessment protocol included AIS neurological examination as described in the International Standards for Neurological and Functional Classification of Spinal Cord Injury Patients; ${ }^{14)}$ standard electromyography (EMG) after asking the subject to move particular muscles; somatosensory-evoked potentials (SSEPs) that were cortically recorded after tibial nerve stimulation; urodynamic studies; full spinal cord MRI scans; otolaryngological evaluation including a general ear, nose, and throat examination, nasal endoscopy, olfactory evaluation, and computed tomography scan of the nose and paranasal sinuses; and psychological assessment. Psychological testing was performed to detect conditions such as active psychosis, major depression, anxiety disorder, severe mood disorder, suicidal behavior, alcohol addiction, drug addiction, low cognitive resources, and unrealistic expectations 
Table 2 Olfactory mucosa autograft transplant outcome measures

\begin{tabular}{l}
\hline Safety measures \\
\hline Postoperative subcutaneous fluid collection \\
Postoperative meningitis \\
Postoperative nasal bleeding \\
Postoperative infection in the nasal cavity \\
Impaired olfaction \\
Neoplastic tissue overgrowth at the transplantation site \\
New sensory disturbance \\
Involuntary muscle spasm \\
\hline Efficacy measures \\
Improved AIS \\
Extent of change in ASIA score \\
EMG \\
MEP \\
SSEP \\
Urological improvement
\end{tabular}

AIS: American Spinal Injury Association Impairment Scale, ASIA: American Spinal Injury Association, EMG: electromyograph, MEP: motor evoked potential, SSEP: somatosensory evoked potential.

about treatment results. Pain was assessed via interviews in which patients were asked to identify painful areas, describe the pain using standard descriptors, and identify temporal aspects of pain.

Motor evoked potentials (MEPs) to bifocal transcranial magnetic stimulation (TMS) were evaluated in the bilateral rectus femoris muscles. TMS was performed with a figure-8 coil (diameter, $7 \mathrm{~cm}$ ) using the MagPro 100 (MagVenture A/S, Denmark). Navigation-guided TMS (Brainsight ${ }^{\circledR}$ Frameless 1.5; Rogue Research Inc., Montreal, Canada) was used to target the optimal position of each stimulation point. The coil was positioned over the leg area of the primary motor cortex. The intensity of the magnetic stimulus was expressed as a percentage of the maximal stimulator output.

Patients' neurological findings were evaluated preoperatively and $12,24,36,48$, and 96 weeks after OMA. The duration of follow-up was 96 weeks postoperatively.

This phase I/II non-randomized, non-controlled prospective study was approved by the Ethical Committee of the Osaka University Medical School in Osaka, Japan. All procedures were performed after obtaining written informed consent from each patient.

\section{Results}

\section{Safety}

No serious adverse events occurred in our series. Subcutaneous accumulation of cerebrospinal fluid was not observed along the incision in any patient. All patients experienced an impaired sense of smell but regained smell within 12 weeks after surgery without any treatments. No meningitis, nasal infection, or neoplasm was observed in any patient after surgery.

\section{Efficacy}

ASIA scoring assessments (motor): The data obtained using the ASIA motor scores are summarized in Table 3 and Fig. 1. No change in the ASIA motor score was observed in three cases, but five other cases demonstrated an improvement in motor function below the level of the injury. The preoperative postrehabilitation ASIA motor score improved from 50 in all cases to 52 in case 2, 60 in case 4, 52 in case 6,55 in case 7 , and 58 in case 8 at 96 weeks after OMA. The average preoperative post-rehabilitation ASIA motor score was 50 . The score was $50.4 \pm 1.1$ (range, 50-53) at 12 weeks after OMA, $51.4 \pm 2.4$ (range, 50-57) at 24 weeks after OMA, $51.9 \pm 2.3$

Table 3 American Spinal Injury Association motor score

\begin{tabular}{|c|c|c|c|c|c|c|c|}
\hline & $\begin{array}{c}\text { Before } \\
\text { preoperative } \\
\text { rehabilitation }\end{array}$ & $\begin{array}{c}\text { Post } \\
\text { preoperative } \\
\text { rehabilitation }\end{array}$ & $\begin{array}{c}12 \text { wks } \\
\text { after OMA }\end{array}$ & $\begin{array}{c}24 \text { wks } \\
\text { after OMA }\end{array}$ & $\begin{array}{c}36 \text { wks } \\
\text { after OMA }\end{array}$ & $\begin{array}{c}48 \text { wks } \\
\text { after OMA }\end{array}$ & $\begin{array}{c}96 \mathrm{wks} \\
\text { after OMA }\end{array}$ \\
\hline Case 1 & 50 & 50 & 50 & 50 & 50 & 50 & 50 \\
\hline Case 2 & 50 & 50 & 50 & 52 & 52 & 52 & 52 \\
\hline Case 3 & 50 & 50 & 50 & 50 & 50 & 50 & 50 \\
\hline Case 4 & 50 & 50 & 50 & 52 & 52 & 54 & 60 \\
\hline Case 5 & 50 & 50 & 50 & 50 & 50 & 50 & 50 \\
\hline Case 6 & 50 & 50 & 50 & 50 & 52 & 52 & 52 \\
\hline Case 7 & 50 & 50 & 50 & 50 & 52 & 55 & 55 \\
\hline Case 8 & 50 & 50 & 53 & 57 & 57 & 58 & 58 \\
\hline
\end{tabular}

OMA: olfactory mucosa autograft, wks: weeks. 


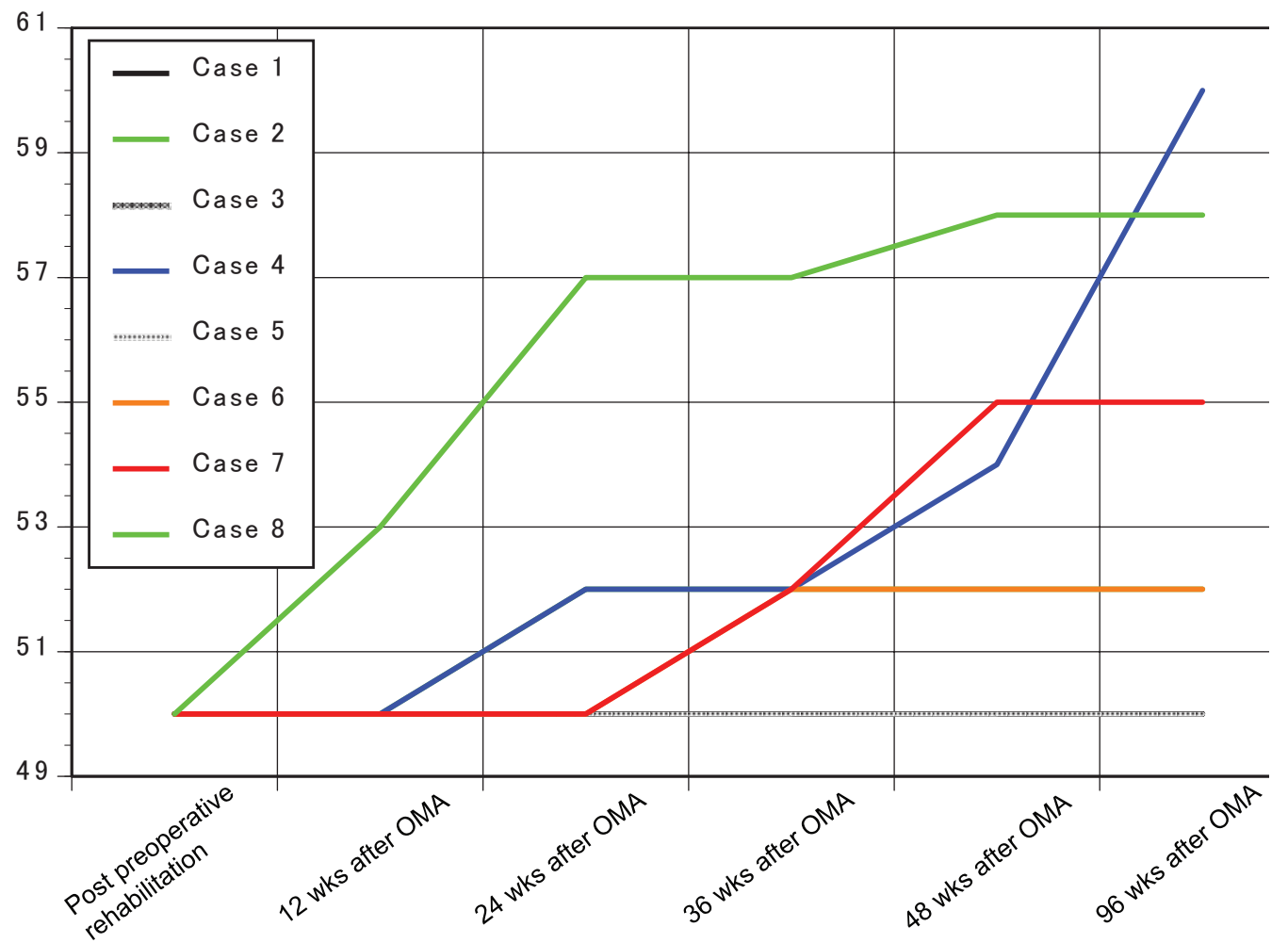

Fig. 1 ASIA motor scores. The preoperative post-rehabilitation ASIA motor score improved from 50 in all cases to 52 in case 2,60 in case 4,52 in case 6, 55 in case 7, and 58 in case 8 at 96 weeks after OMA. ASIA: American Spinal Injury Association, OMA: olfactory mucosa autograft.

(range, 50-57) at 36 weeks after OMA, $52.6 \pm 2.9$ (range, 50-58) at 48 weeks after OMA, and $53.4 \pm$ 3.9 (range, 50-60) at 96 weeks after OMA.

ASIA scoring assessments (sensory pinprick and light touch scores): No remarkable score changes were observed in any patients.

AIS grade: AIS grade did not improve in three cases. However, the grade improved from $A$ to $C$ in four cases and from $B$ to $C$ in one case.

\section{Electrophysiological assessment}

EMG assessment (voluntary movement): New voluntary activity in response to voluntary effort was documented by EMG at 48 weeks after surgery in cases 2, 4, 6, 7, and 8. In cases 2, 6, 7, and 8, voluntary activity was recognized in the right gluteus maximus and quadriceps muscles. In cases 4 and 7 , activity was seen in the bilateral anterior tibial and gastrocnemius muscles, as well as in the left gluteus maximus and hamstring muscles. In case 4 , activity was recognized in the bilateral gluteus maximus and quadriceps muscles, as well as in the left hamstring, anterior tibial, and gastrocnemius muscles.

SSEP assessment: No new SSEP findings derived from tibial nerve stimulation were recorded at the cortical level in any patient.
Urodynamic studies: No urge to urinate was detected before or after transplantation, and all patients remained unable to urinate voluntarily.

MEPs: MEPs were not observed before transplantation in any patient. MEPs were recorded at 48 weeks after transplantation in case 4 (Fig. 2) but not in any other patient.

MRI findings: MRI scans at 96 weeks after transplantation revealed fairly complete filling of cavities and heterogeneous intensity on T1- and T2-weighted images. Gadolinium-enhanced MRI revealed heterogeneous enhancement of grafts. No evidence of neoplastic tissue overgrowth was observed in any patient (Fig. 3).

\section{Daily living}

All patients described improvement in trunk balance, and consequently, they were able to sit for a long time and/or shampoo by themselves or press an elevator button easily. Some patients were able to turn over in bed.

\section{Discussion}

Our rationale for selecting chronic SCI patients (more than 12 months from injury) was to circumvent 


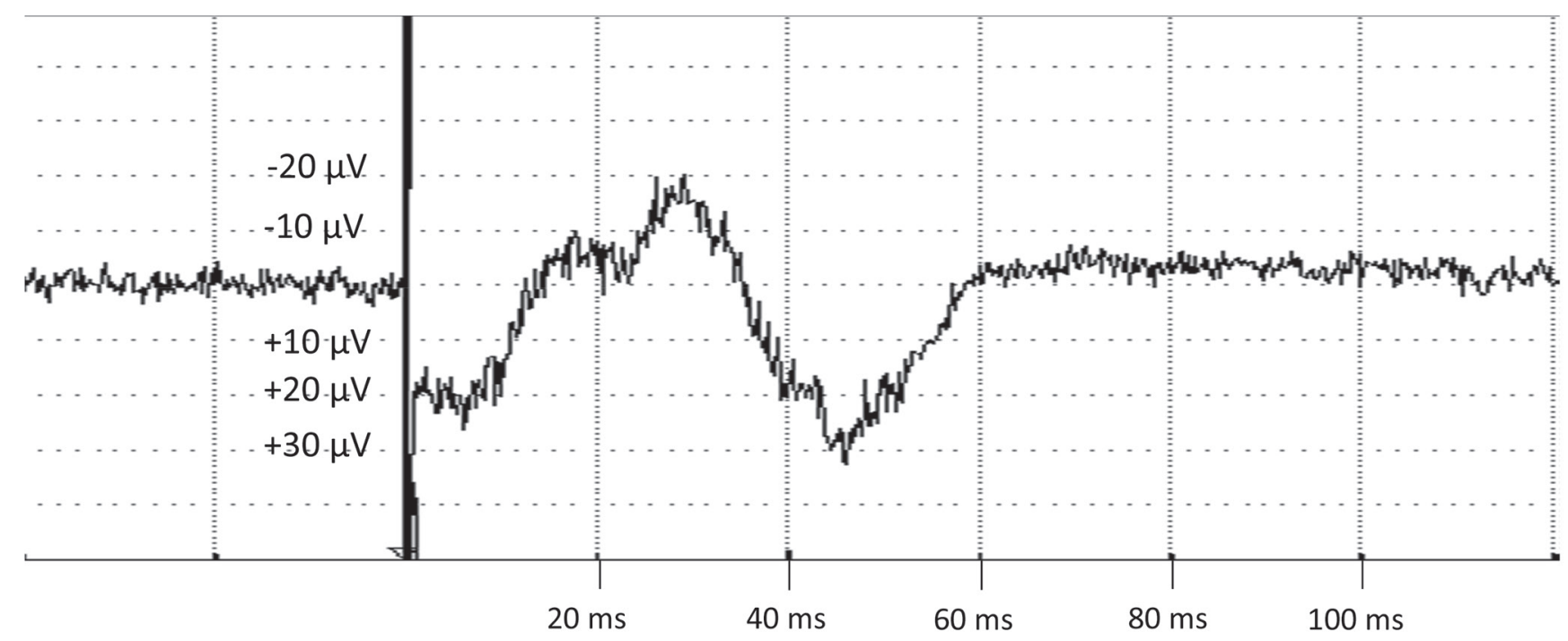

Fig. 2 This image shows the motor evoked potential that was elicited in response to bifocal transcranial magnetic stimulation of the rectus femoris muscles.
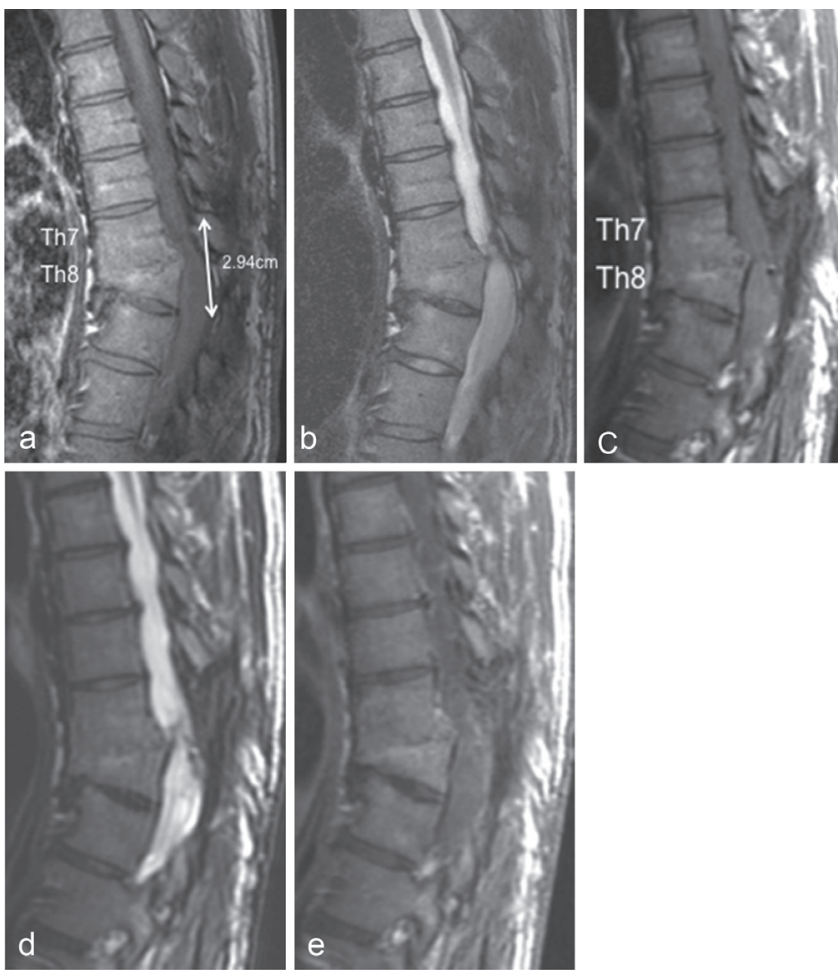

Fig. 3 Magnetic resonance imaging (MRI). a: $\mathrm{T}_{1}$-weighted sagittal image before transplantation shows atrophic changes in the thoracic spinal cord. $b$ : $\mathrm{T}_{2}$-weighted sagittal image before transplantation shows an intramedullary high-intensity area. c, d: MRI at 96 weeks after transplantation shows fairly complete filling of cavities with heterogeneous intensity on $T_{1}$ - (c) and $T_{2}$-weighted (d) images. e: Gadolinium-enhanced images also show heterogeneous enhancement of the grafts. No evidence of neoplastic tissue overgrowth was observed during the initial follow-up period of 96 weeks. spontaneous recovery bias. ${ }^{11)}$ Furthermore, all patients underwent preoperative rehabilitation ( 8 weeks) to ensure their neurological status. These patients were considered to have chronic complete SCI.

Walking improvements have not been achieved in patients with clinically sensorimotor-complete SCI with any treatment. ${ }^{15,16)}$ In this report, continuous and combined intensive training after OMA triggered limited voluntary movement and induced limited reconstruction of severely damaged neural circuits in chronic sensorimotor-complete SCI. These events were confirmed by the observation of MEPs in one case.

The information about OMA derived from the studies of Lima et al. is invaluable to basic and clinical researchers investigating regeneration in chronic SCI. Their pioneering work in this field revealed that OMA is fairly safe, feasible, and potentially beneficial. ${ }^{10,13)}$ OMA is advantageous because it involves transplantation of whole tissue that is rich in factors that may facilitate neuronal regeneration. We have performed further basic studies in rats of olfactory mucosa transplantation that supported the feasibility of this procedure. ${ }^{17-20)}$

Spinal cord reconstruction using implantation of cells from various sources has recently gained attention. ${ }^{21,22)}$ Neuronal stem cells (NSCs) have the potential to differentiate into both neuronal and glial cells and are therefore prime candidates for cell replacement therapy following CNS injury. NSCs constitutively secrete significant quantities of several neurotrophic factors that support host axonal regeneration after SCI. ${ }^{23)}$ Partial restoration of function after spinal cord contusion has been 
achieved by injecting neural/glial precursor NSCs differentiated in vitro from mouse embryonic stem cells into the lesion 9 days after injury. ${ }^{24)}$ However, implantation of NSCs alone does not produce any significant restorative effect because the majority of the NSCs grafted into the spinal cord differentiate into an astrocytic phenotype. ${ }^{23,25)}$ Although astrocytes can secrete neurotrophic factors and limit inflammation, extensive astroglial scarring within the lesioned area blocks axonal growth.

One of the major disadvantages associated with implantation or injection of cells alone is the limited proportion of viable cells that survive at the injury site after the procedure, as cells tend to migrate away from the injury site. ${ }^{26)}$ To achieve significant functional reconstruction of the spinal cord after SCI, either populating the lesion sites with tissuespecific regeneration-competent cells or activating endogenous neural progenitor cells to replace or rescue dying cells is necessary. ${ }^{27)}$ The olfactory mucosa appears to be an excellent autologous source of adult neuronal precursor cells. It is easily accessible for a biopsy ${ }^{28)}$ and contains neurons and sustentacular cells that self-renew throughout life ${ }^{3-5}$ as well as olfactory ensheathing cells that have shown promise in repairing SCI. ${ }^{6-9)}$ These characteristics make the olfactory mucosa an attractive tissue for potential applications in axonal regeneration. Lima et al. used the following inclusion criteria: ASIA impairment grade A or B; age 18-40 years; cervical spinal cord lesion less than $3 \mathrm{~cm}$ or thoracic spinal cord lesion less than $4 \mathrm{~cm}$; absence of significant nasal and paranasal sinus pathology; and absence of additional serious medical problems, brain disease, or psychological problems. However, they were unable to elicit expression of MEPs, which demonstrate electrophysiological conductivity.

We were able to elicit MEPs in one case. MEPs reflect conductivity in the CNS, including the corticospinal tract. ${ }^{29,30)}$ MEPs induced with TMS allow objective assessment of the integrity of human motor circuitry comprising both the corticospinal tract and peripheral motor nerves. ${ }^{31,32)}$ Our report is the first observation of MEPs following any treatment, indicating the partial recovery of electrophysiological conductivity after complete chronic SCI.

One report has described a serious event following OMA. Brian et al. reported a human spinal cord mass following OMA. ${ }^{33)}$ In their report, an 18-yearold woman who sustained a complete SCI at T10-11 underwent OMA. She developed back pain 8 years later, and imaging revealed an intramedullary spinal cord mass at the site of OMA that required resection.
Intraoperative findings revealed expansion of the spinal cord with a multicystic mass containing large amounts of thick mucus-like material. Histological examination and immunohistochemical staining revealed that the mass was composed mostly of cysts lined by respiratory epithelium, submucosal glands with goblet cells, and intervening nerve twigs. Thus, the mass in the spinal cord appeared to contain respiratory mucosa, which does not affect spinal regeneration, ${ }^{17,18,20,34,35)}$ and not olfactory mucosa. Unfortunately, respiratory mucosa may have been transplanted instead of olfactory mucosa in their case. We absolutely agree with their comment that safety monitoring of all patients who have received cell transplantation and neural stem cell implantation should continue for many years.

This pilot study of OMA included only eight patients. Discussing the feasibility of OMA is difficult. However, we showed improvement in both the AIS grade and ASIA motor score in five patients, as well as the expression of MEPs in one patient. OMA may be an excellent strategy for overcoming chronic complete SCI.

\section{Conflicts of Interest Disclosure}

The authors have no disclosures to report.

\section{References}

1) McDonald JW, Sadowsky C: Spinal-cord injury. Lancet 359: 417-425, 2002

2) Filbin MT: Axon regeneration: vaccinating against spinal cord injury. Curr Biol 10: R100-R103, 2000

3) Calof AL, Bonnin A, Crocker C, Kawauchi S, Murray RC, Shou J, Wu HH: Progenitor cells of the olfactory receptor neuron lineage. Microsc Res Tech 58: 176-188, 2002

4) Cunningham AM, Manis PB, Reed RR, Ronnett GV: Olfactory receptor neurons exist as distinct subclasses of immature and mature cells in primary culture. Neuroscience 93: 1301-1312, 1999

5) Roisen FJ, Klueber KM, Lu CL, Hatcher LM, Dozier A, Shields CB, Maguire S: Adult human olfactory stem cells. Brain Res 890: 11-22, 2001

6) Barnett SC, Riddell JS: Olfactory ensheathing cells (OECs) and the treatment of CNS injury: advantages and possible caveats. J Anat 204: 57-67, 2004

7) Smith PM, Lakatos A, Barnett SC, Jeffery ND, Franklin RJ: Cryopreserved cells isolated from the adult canine olfactory bulb are capable of extensive remyelination following transplantation into the adult rat CNS. Exp Neurol 176: 402-406, 2002

8) Li Y, Field PM, Raisman G: Repair of adult rat corticospinal tract by transplants of olfactory ensheathing cells. Science 277: 2000-2002, 1997 
9) Ramón-Cueto A, Valverde F: Olfactory bulb ensheathing glia: a unique cell type with axonal growth-promoting properties. Glia 14: 163-173, 1995

10) Lima C, Escada P, Pratas-Vital J, Branco C, Arcangeli CA, Lazzeri G, Maia CA, Capucho C, Hasse-Ferreira A, Peduzzi JD: Olfactory mucosal autografts and rehabilitation for chronic traumatic spinal cord injury. Neurorehabil Neural Repair 24: 10-22, 2010

11) Ditunno JF Jr: Functional assessment measures in CNS trauma. J Neurotrauma 9(Suppl 1): S301-S305, 1992

12) Association ASC: ASIA International Standards for Neurological Classification of Spinal Cord Injury, Revised. Spinal Cord Association, 2003

13) Lima C, Pratas-Vital J, Escada P, Hasse-Ferreira A, Capucho C, Peduzzi JD: Olfactory mucosa autografts in human spinal cord injury: a pilot clinical study. J Spinal Cord Med 29: 191-203; discussion 204-206, 2006

14) Baranowski P: Application of the International Standards for the Neurological and Functional Classification of Spinal Cord Injuries (the ASIA scale). Ortop Traumatol Rehabil 2: 31-34, 2000

15) Dietz V, Colombo G, Jensen L: Locomotor activity in spinal man. Lancet 344: 1260-1263, 1994

16) Harkema S, Gerasimenko Y, Hodes J, Burdick J, Angeli C, Chen Y, Ferreira C, Willhite A, Rejc E, Grossman RG, Edgerton VR: Effect of epidural stimulation of the lumbosacral spinal cord on voluntary movement, standing, and assisted stepping after motor complete paraplegia: a case study. Lancet 377: 1938-1947, 2011

17) Iwatsuki K, Yoshimine T, Kishima H, Aoki M, Yoshimura K, Ishihara M, Ohnishi Y, Lima C: Transplantation of olfactory mucosa following spinal cord injury promotes recovery in rats. Neuroreport 19: 1249-1252, 2008

18) Aoki M, Kishima H, Yoshimura K, Ishihara M, Ueno M, Hata K, Yamashita T, Iwatsuki K, Yoshimine T: Limited functional recovery in rats with complete spinal cord injury after transplantation of wholelayer olfactory mucosa: laboratory investigation. J Neurosurg Spine 12: 122-130, 2010

19) Moriwaki T, Iwatsuki K, Mochizuki-Oda N, Ohnishi Y, Ishihara M, Umegaki M, Ninomiya K, Yoshimine T: Presence of trans-synaptic neurons derived from olfactory mucosa transplanted after spinal cord injury. Spine (Phila Pa 1976) 39: 1267-1273, 2014

20) Ishihara M, Mochizuki-Oda N, Iwatsuki K, Kishima H, Iwamoto Y, Ohnishi Y, Umegaki M, Yoshimine T: A new three-dimensional axonal outgrowth assay for central nervous system regeneration. J Neurosci Methods 198: 181-186, 2011

21) Keyvan-Fouladi N, Raisman G, Li Y: Functional repair of the corticospinal tract by delayed transplantation of olfactory ensheathing cells in adult rats. J Neurosci 23: 9428-9434, 2003

22) Ogawa Y, Sawamoto K, Miyata T, Miyao S, Watanabe M, Nakamura M, Bregman BS, Koike M, Uchiyama
Y, Toyama Y, Okano H: Transplantation of in vitroexpanded fetal neural progenitor cells results in neurogenesis and functional recovery after spinal cord contusion injury in adult rats. J Neurosci Res 69: 925-933, 2002

23) Han SS, Kang DY, Mujtaba T, Rao MS, Fischer I: Grafted lineage-restricted precursors differentiate exclusively into neurons in the adult spinal cord. Exp Neurol 177: 360-375, 2002

24) McDonald JW, Liu XZ, Qu Y, Liu S, Mickey SK, Turetsky D, Gottlieb DI, Choi DW: Transplanted embryonic stem cells survive, differentiate and promote recovery in injured rat spinal cord. Nat Med 5: 1410-1412, 1999

25) Cao QL, Zhang YP, Howard RM, Walters WM, Tsoulfas P, Whittemore SR: Pluripotent stem cells engrafted into the normal or lesioned adult rat spinal cord are restricted to a glial lineage. Exp Neurol 167: 48-58, 2001

26) Okada S, Ishii K, Yamane J, Iwanami A, Ikegami T, Katoh H, Iwamoto Y, Nakamura M, Miyoshi H, Okano HJ, Contag CH, Toyama Y, Okano H: In vivo imaging of engrafted neural stem cells: its application in evaluating the optimal timing of transplantation for spinal cord injury. FASEB J 19: 1839-1841, 2005

27) Stocum DL: Stem cells in CNS and cardiac regeneration. Adv Biochem Eng Biotechnol 93: 135-159, 2005

28) Féron F, Perry C, McGrath JJ, Mackay-Sim A: New techniques for biopsy and culture of human olfactory epithelial neurons. Arch Otolaryngol Head Neck Surg 124: 861-866, 1998

29) Rossini PM, Barker AT, Berardelli A, Caramia MD, Caruso G, Cracco RQ, Dimitrijević MR, Hallett M, Katayama Y, Lücking CH: Non-invasive electrical and magnetic stimulation of the brain, spinal cord and roots: basic principles and procedures for routine clinical application. Report of an IFCN committee. Electroencephalogr Clin Neurophysiol 91: 79-92, 1994

30) Rossini PM: The anatomic and physiologic bases of motor-evoked potentials. Neurol Clin 6: 751-769, 1988

31) Calancie B, Alexeeva N, Broton JG, Suys S, Hall A, Klose KJ: Distribution and latency of muscle responses to transcranial magnetic stimulation of motor cortex after spinal cord injury in humans. $J$ Neurotrauma 16: 49-67, 1999

32) Curt A, Keck ME, Dietz V: Functional outcome following spinal cord injury: significance of motorevoked potentials and ASIA scores. Arch Phys Med Rehabil 79: 81-86, 1998

33) Dlouhy BJ, Awe O, Rao RC, Kirby PA, Hitchon PW: Autograft-derived spinal cord mass following olfactory mucosal cell transplantation in a spinal cord injury patient: case report. J Neurosurg Spine 21: 618-622, 2014

34) Iwatsuki K, Yoshimine T, Sankai Y, Tajima F, Umegaki M, Ohnishi Y, Ishihara M, Ninomiya K, Moriwaki 
T: Involuntary muscle spasm expressed as motor evoked potential after olfactory mucosa autograft in patients with chronic spinal cord injury and complete paraplegia. J Biomed Sci Eng 6: 908-916, 2013

35) Nakayama J, Takao T, Kiuchi H, Yamamoto K, Fukuhara S, Miyagawa Y, Aoki M, Iwatsuki K, Yoshimine T, Ueno M, Yamashita T, Nonomura N, Tsujimura A, Okuyama A: Olfactory mucosal transplantation after spinal cord injury improves voiding efficiency by suppressing detrusor-sphincter dyssynergia in rats. J Urol 184: 775-782, 2010

Address reprint requests to: Koichi Iwatsuki, MD, $\mathrm{PhD}$, Department of Neurosurgery, Osaka University Medical School, 2-2 Yamadaoka, Suita, Osaka 565-0871, Japan.

e-mail: kiwatsuki@nsurg.med.osaka-u.ac.jp 